\title{
Flexural behaviour of composite slim floor beams
}

\author{
T. Sheehan ${ }^{a *}$, X. Dai ${ }^{a}$, J. Yang ${ }^{\mathrm{a}}$, K. Zhou ${ }^{\mathrm{a}}$ and D. Lam ${ }^{\mathrm{a}}$ \\ ${ }^{a}$ University of Bradford, United Kingdom \\ *corresponding author, e-mail address: t.sheehan@bradford.ac.uk, x.dai@bradford.ac.uk, \\ j.yang17@bradford.ac.uk, k.zhou1@bradford.ac.uk,d.lam1@bradford.ac.uk
}

\begin{abstract}
Composite slim floor beams comprise a steel section embedded in a concrete slab, offering the advantages of a steel-concrete composite structure combined with a reduced floor depth. Several mechanisms contribute to the shear connection in this type of beam, such as headed studs, friction and clamping effects and the using of reinforcement bars passing through holes in the steel beam web. However, to date, nobody has systematically identified these mechanisms and Eurocode 4 does not provide specific design guidance for slim floor beams. Hence, a series of shear beam tests and flexural beam tests were carried out in order to assess the degree of shear connection and connector capacity in these beams. The test set-up is described including different arrangements of shear connectors for each specimen. The paper presents the findings from the flexural beam tests. The results are compared with those from the previous shear beam tests. Numerical models will be developed in future to extend the data and include a wider range of parameters. The data will also be used to improve understanding of this type of beam and will lead to the provision of specific design guidelines for slim floor beams.
\end{abstract}

Keywords: composite construction; slim floor beam; shear connector; experimental study

\section{Introduction}

Composite beams consisting of a steel Isection and concrete slab are very popular, particularly in multi-storey buildings and carparks, since the components are arranged in such a way as to optimise the material performance, enabling long spans to be achieved. Slim-floor beams are an innovative variant of this, in which the steel beam is embedded within the concrete slab, reducing the overall beam depth and saving valuable vertical space. However, there are some differences between slim-floor beams and other composite beams - slim-floor beams usually employ a highly asymmetric steel section, and hence the plastic neutral axis is located at a lower position, leading to larger strains in the concrete than in other composite beams. While other types of composite beam are well understood, and some research has been carried out on slim floor beams to date [1-3], further work is needed to gain a better understanding of their behaviour.

In addition to the different strain profile, the position of the beam within the concrete increases the number of ways in which the shear stresses can be transferred between the two materials. While other types of composite beam typically use shear connectors, welded/bolted to the top flange of the beam and embedded in the slab, shear connection in slim-floor beams may be achieved via connectors in the web of the steel section and clamping/friction effects between the steel beam and concrete slab.

This paper presents the results from tests on a number of slim-floor beams in bending, using different arrangements of shear connectors, and compares the results with a previous series of tests in which the beams were subjected to shear. All of this work is being carried out in the University of Bradford as part a research project entitled 'Slim-Floor Beams - Preparation of application rules in view of improved safety, functionality and LCA', in collaboration with the University of Stuttgart, Universita degli Studi di Trento, the Steel Construction Institute, LINDAB S.A. and ArcelorMittalBelval and Differdange. The work is funded by the European Research Fund for Coal and Steel. 


\section{Test set-up}

A total of 9 specimens were to be tested in flexure. This paper reports the results from the first six tests. The specimen details and testing procedure are described in the following sections.

\subsection{Specimen details}

The six beams tested were named BT1a, BT3, BT4, BT6, BT7 and BT8. Fig. 1 shows a crosssection view of BT1a. This was the basic testspecimen type, comprising a $240 \mathrm{~mm}$ deep concrete slab (upper portion $120 \mathrm{~mm}$ deep), encasing a HEB200 beam section, with a $400 \times$ $15 \mathrm{~mm}$ steel plate welded to the underside. Shear connection between the materials was provided by $1400 \mathrm{~mm}$ long steel bars passing through a 40 $\mathrm{mm}$ diameter hole in the steel beam web. These were placed at $500 \mathrm{~mm}$ spacing, designed to provide a degree of shear connection equal to $40 \%$. A252 mesh was employed near the top of the concrete slab to prevent failure of the concrete under hogging moment. The beam spanned $6 \mathrm{~m}$ between the two supports and was loaded at two points along the length, each at the centre of the cross-section and at a distance of $2.25 \mathrm{~m}$ from the end supports, as depicted in Fig. 2. Specimen BT3 was the same as BT1a, except that it utilised a greater number of transverse bars to provide a degree of shear connection equal to $100 \%$. Conversely, BT4 had the same configuration, but with fewer bars, to provide $25 \%$ shear connection. BT6 had no shear connectors and load was applied eccentrically, BT7 had horizontal shear studs welded onto the beam web instead of transverse bars, BT8 had larger holes in the beam web ( $80 \mathrm{~mm}$ diameter).

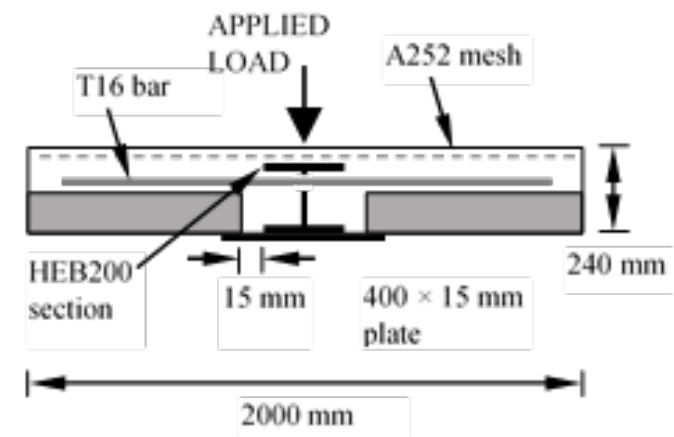

Fig. 1. Cross-section view of typical specimen

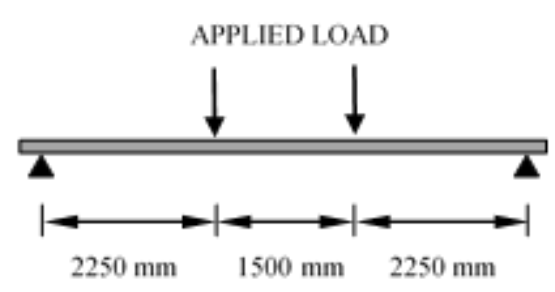

Fig. 2. Side-view of specimen

\subsection{Instrumentation and test procedure}

Strain gauges and LVDTs were used to monitor the strains and deflections at different locations along the specimen. Nine LVDTs were used to measure the vertical deflection of the beam under applied loading. One of these was placed directly under each of the loading points and another LVDT was placed halfway between these two, at the mid-span. Six LVDTs were positioned at the edges of the slab, three on each side, in line with the ones in the centre. An additional two LVDTs were used at the specimen ends to measure the slip between the concrete slab and steel section. The positions of the LVDTs are shown in a plan view in Fig. 3.

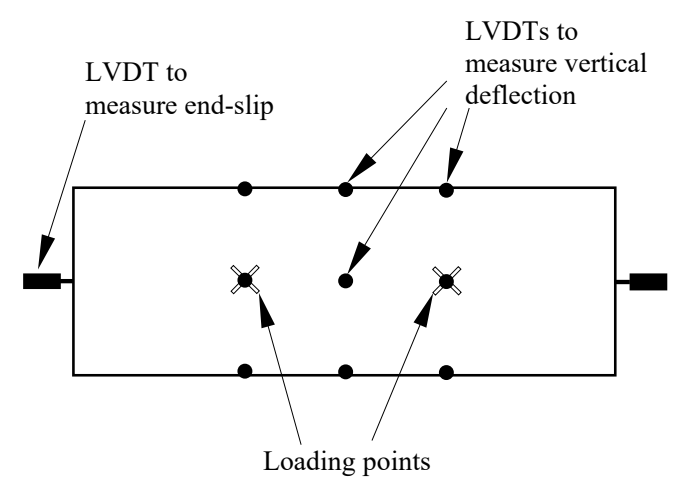

Fig. 3. Position of LVDTs on beam

Strain gauges were used on the steel beam, shear connectors and concrete slab to monitor the local deformations on these elements during the test. Six strain gauges were attached to the upper flange of the steel beam and six gauges were glued to the bottom steel plate, within 1500 $\mathrm{mm}$ of the mid-span. Strain gauges were placed on the surface of the transverse bars (or the surface of the body of the shear studs). Due to the data logging system, only a limited number of strains could be monitored, and hence the setup varied from specimen to specimen. For BT4, two strain gauges were used for each transverse bar: one at the centre, and one at a $50 \mathrm{~mm}$ offset from the centre. For the other cases, only one strain gauge could be used per connector. For 
BT3 and BT7, only certain connectors had a strain gauge: the $1^{\text {st }}, 2^{\text {nd }}, 4^{\text {th }}$ and $6^{\text {th }}$ connectors from each end. In specimens BT6 and BT8, strains were also measured on the web of the beam. The longitudinal strain was measured on the top of the concrete slab at the mid-span, at three locations, going from the edge toward the middle.

Load was applied to the beam using a hydraulic actuator and a system of spreader beams. During the test, the load was applied slowly, in $20 \mathrm{kN}$ increments during the early stages of the test, and $5 \mathrm{~mm}$ displacement increments during the later stages, until failure occurred. The observations and test results will be discussed in further detail in the subsequent sections.

\section{Results}

\subsection{Load-deflection behaviour}

Overall, the six specimens exhibited fairly similar behaviour during the test. The relationship between load and mid-span deflection, shown in Fig. 4, was initially fairly stiff and linear. At around $200-250 \mathrm{kN}$, depending on the specimen, some initial cracks occurred. A drop in load was noticed in specimens BT1a, BT3, BT4 and BT6, which was more pronounced in BT4 than in the other cases. As the applied load increased the stiffness suddenly reduced, to approximately half of the original stiffness in some cases. As the load was increased further, the mid-span deflection continued to increase, along with the crack widths. During the final phase of the test, the stiffness reduced further, as the load reached a plateau, and the test was continued for each of the four specimens until they could withstand no further load. BT4 was unloaded and reloaded again at the end of the test, but a higher load could not be attained upon reloading. BT8 was unloaded and reloaded at an earlier stage of the test owing to an issue with the loading set-up, but this did not appear to affect the load-deflection relationship and curve continued smoothly upon reloading.
As described in the previous section, the load was applied in increments, and as can be seen in Fig. 4, the load tended to drop towards the end of each increment, reaching a minimum value before the next load increment was applied. Using the lower bound curve passing through these minimum points, the maximum applied load and corresponding bending moment (load/2 $\times 2.25 \mathrm{~m}$ ) can be found, and these are presented for each test specimen in Table 1. As expected, BT6 had the lowest failure load, with higher loads resisted by the specimens designed for higher degrees of shear connection. The larger web holes in BT8 enabled it to resist an extra 36 $\mathrm{kN}$ compared with BT1a. The only surprising outcome was the maximum load resisted by specimen BT7, with shear studs instead of transverse bars. The maximum load surpassed that of BT 1a by over 33\%. In the previous shear beam tests, no significant difference was noticed in terms of maximum load between the specimens using transverse bars and the specimens using studs. Comparing the other test specimens with the previous shear beam series, specimen BT1a resisted a total bending moment of $565 \mathrm{kN} \cdot \mathrm{m}$, which is slightly higher than that resisted by the equivalent specimen SBT2 (529 $\mathrm{kN} \cdot \mathrm{m}$ ) in the previous shear beam tests. BT6 and BT8 also resisted larger moments $(455 \mathrm{kN} \cdot \mathrm{m}$ and $605 \mathrm{kN} \cdot \mathrm{m})$ than the equivalent shear beams SBT3 and SBT5 $(407 \mathrm{kN} \cdot \mathrm{m}$ and $575 \mathrm{kN} \cdot \mathrm{m})$. It should be noted that the failure modes of the tests were slightly different, with shear failure dominating the previous test series, while flexural failure was prevalent in the current series.

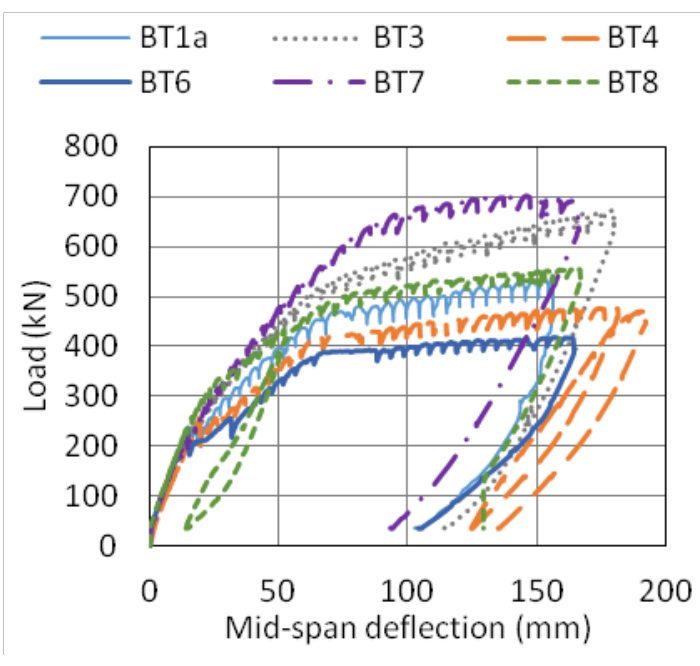

Fig. 4 Relationship between load and mid-span deflection 
Table 1. Maximum loads and corresponding bending moments

\begin{tabular}{ccc}
\hline Specimen & $\begin{array}{c}\text { Load } \\
(\mathbf{k N})\end{array}$ & $\begin{array}{c}\text { Bending moment } \\
(\mathbf{k N m})\end{array}$ \\
\hline BT1a & 502 & 565 \\
BT3 & 645 & 725 \\
BT4 & 461 & 519 \\
BT6 & 405 & 455 \\
BT7 & 676 & 760 \\
BT8 & 538 & 605 \\
\hline
\end{tabular}

No obvious difference was observed between the deflections at the edge of the slab and the deflections in the centre. This was to be expected as the bending specimens are longer than the previously tested shear beams, and the deflected shape was predominantly sagging in the longitudinal direction. In most cases, the deflections were of a similar magnitude at both the mid-span and loading points, with one edge having a slightly larger deflections than the centre and other edge. For specimens BT7 and BT8, the central mid-span deflection was slightly smaller than either of the edges, which might be expected for BT7, where studs were used instead of transverse bars, but this only applied to the mid-span and not the deflections at the loading points.

A comparison between the deflections at the centre (L1) and edges (L8 and L11) of the slab at a loading point (750 $\mathrm{mm}$ from the mid-span) are shown in Fig. 5 for specimen BT3 and between the centre (L2) and the edges (L7 and L10) at the mid-span for BT7 are shown in Fig. 6.

The maximum mid-span deflection exceeded $150 \mathrm{~mm}$ in all of the bending tests (span/40). As one would expect, the relative mid-span deflection was greater than that measured in the shear beam tests, which all reached a deflection of magnitude span $/ 50$.

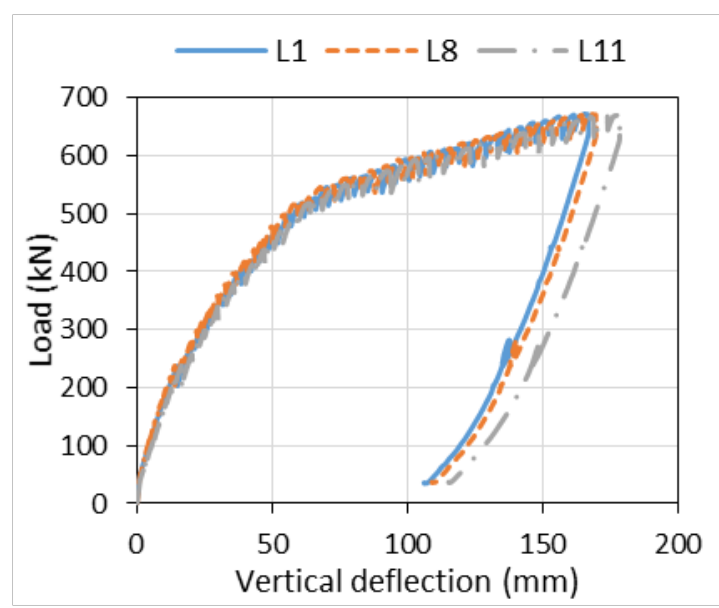

Fig. 5. Relationship between load and deflection at loading point for BT3

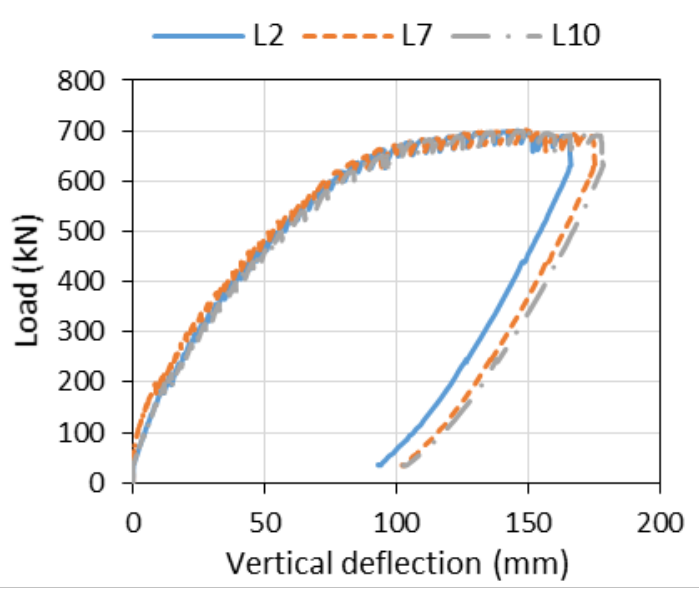

Fig. 6. Relationship between load and deflection at mid-span for BT7

\subsection{Concrete cracking}

During the initial phase of the test there were no obvious cracks in the concrete. The first cracks became visible during the second phase, which commenced at around $200-300 \mathrm{kN}$ for each specimen. Very small vertical cracks were observed in the concrete around the web of the steel beam, as shown for BT7 in Fig 7. During the second phase of the test, these grew in size, and cracks also appeared on the outer edge of the slab, as shown Fig. 8. During the final phase of the test, the cracks became very wide, deep cracks ran along the underside of the slab, connecting the cracks that occurred around the web to the cracks on the outer edge. Longitudinal cracks were also observed on the top of the slab. Comparing the crack pattern with the previous shear beam tests, some small differences were observed. For the shear beam 
tests, the specimens initially failed in shear, with diagonal cracks occurring close to the loading points, and flexural cracks that were vertical and closer to the mid-span only occurred much later in the test. The shear cracks are shown for SBT1a in Fig. 9. For the bending tests, there was a more even distribution of cracks along the specimen length, showing that the failure was predominantly a flexural failure. This is illustrated for SBT1a.

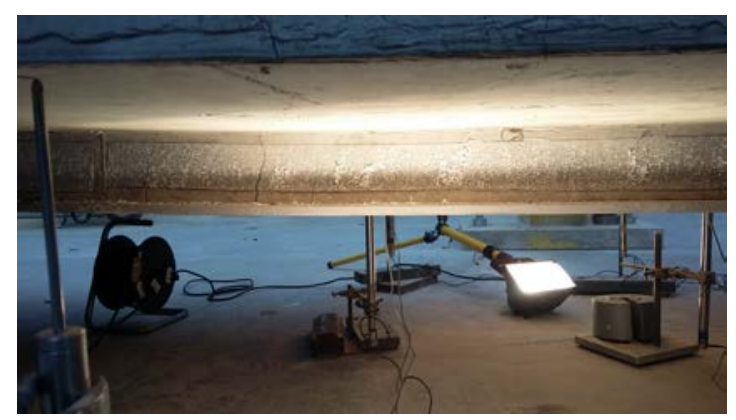

Fig. 7. Concrete cracks around beam web for BT7

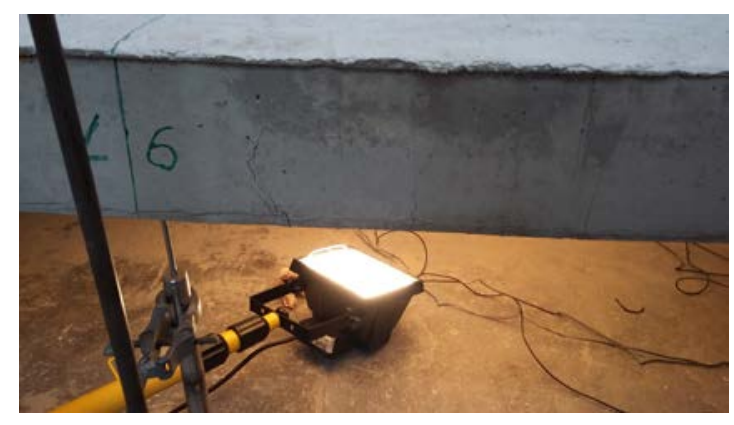

Fig. 8. Concrete cracks on outside edge of lab for BT7

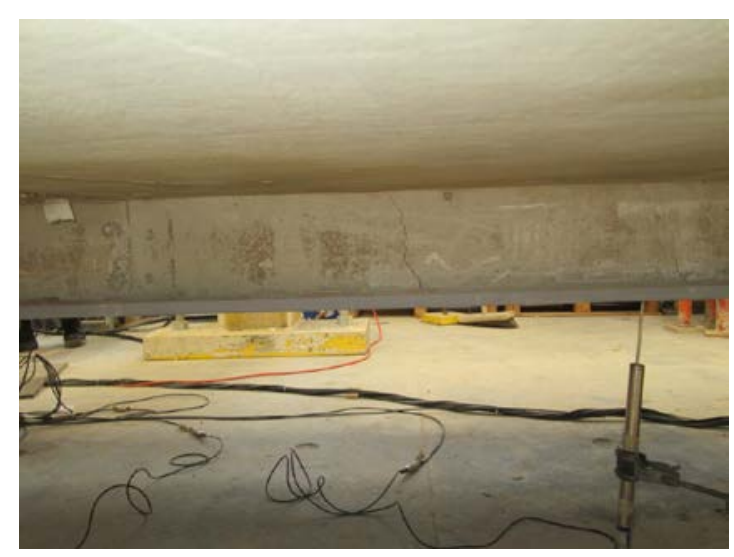

Fig. 9. Shear cracks in SBT1a from previous test series.

\subsection{End-slip}

Fig. 10 presents the relationship between load and end-slip for each of the test specimens. In all cases, the degree of end-slip was very low during the initial phase of the test, and then increased rapidly during the second and third phases. With the exception of specimen BT6, in most cases, the maximum end-slip was between 10 and $20 \mathrm{~mm}$, and similar values were measured at each end. These values were significantly larger than the $6 \mathrm{~mm}$ value of slippage stipulated by Eurocode 4 for ductile shear connector behaviour [4].

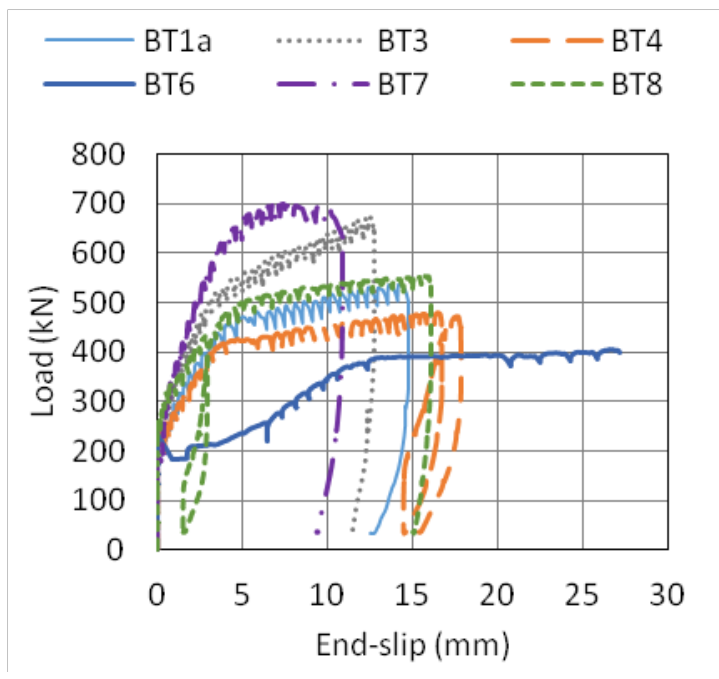

Fig. 10. Relationship between load and end-slip

\subsection{Strains in steel section and concrete}

In most specimens, the top flange of the beam reached the yield strain in compression before the end of the test. The only exception was BT7, which achieved strains of approximately 1000 $\mu \varepsilon$ in five of the six monitoring points. The strains in the bottom plate reached or surpassed the value associated with yielding in tension during the later stages of all of the tests. The strains measured in web were main compressive, and smaller in magnitude than those in the top flange. Fig. 11 presents the strains measured in the top flange, web and bottom plate for BT1a. 


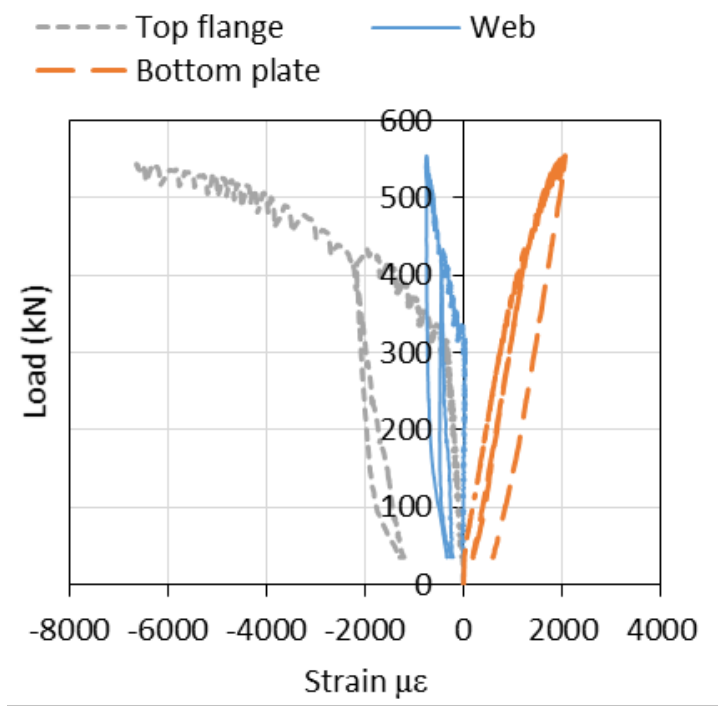

Fig. 11. Strains in steel section for BT8

In most specimens, the strains measured in the concrete reached a maximum value between 1000 and $1500 \mu \varepsilon$, which is lower than the value associated with yielding of the material. Specimen BT7 exhibited slightly larger strains, with strains at one of the monitoring points exceeding $2000 \mu \varepsilon$ and the strains at the other two monitoring points almost reaching $2000 \mu \varepsilon$. This, combined with the difference in top flange strain for BT7 suggests that the use of shear studs instead of transverse bars affected the strain profile of the section. Generally, the beam specimens with the transverse bars performed well, with the strains in the top flange and bottom plate reaching the yield strain before the specimen failed.

The strains measured by the strain gauges on the top flange of the steel and bottom plate at the mid-span are compared between some of the bending specimens (BT1a, BT6, BT7 and BT8) and the equivalent shear specimens (SBT2, SBT3, SBT6 and SBT5 respectively) from the previous test series in Tables 2 and 3. Table 2 presents the strains measured at the transition between the first and second phases of the tests and Table 3 presents the strains measured at the transition between the second and third phases of the tests. In both tables, the position of the neutral axis below the top of the steel section, was estimated assuming a linear strain distribution through the depth of the section and using the average measured values. In Table 2, bending test specimens BT1a and BT8 appear to have neutral axes that are lower in the section than SBT2 and SBT5. The difference is less pronounced between BT7 and SBT6 and the trend is reversed for BT6 and SBT3. In Table 3, BT1a and SBT2 have similar strain profiles and the relationship between BT6 and SBT3 is similar to before. However, in contrast to SBT6, the bottom flange in BT7 has exceeded the yield strain and average strain reading on the top flange has become positive (tensile). In specimen BT8, the top flange has significantly exceeded the yield strain. In these cases it is difficult to reliably estimate the position of the neutral axis based on the measured strains, since some of the strain gauges would have exceeded their working limits and hence further work will be needed at a later stage to examine this.

Table 2. Strains in steel section at end initial yield

\begin{tabular}{cccc}
\hline Specimen & $\begin{array}{c}\text { Top } \\
\text { flange } \\
(\boldsymbol{\mu \varepsilon})\end{array}$ & $\begin{array}{c}\text { Bottom } \\
\text { plate } \\
(\boldsymbol{\mu \varepsilon})\end{array}$ & $\begin{array}{c}\text { Neutral axis } \\
\text { depth }(\mathbf{m m})\end{array}$ \\
\hline BT1a & -642 & 655 & 106 \\
SBT2 & -375 & 839 & 66 \\
BT6 & -228 & 547 & 63 \\
SBT3 & -456 & 763 & 80 \\
BT7 & -220 & 455 & 70 \\
SBT6 & -143 & 345 & 63 \\
BT8 & -544 & 827 & 85 \\
SBT5 & -84 & 771 & 21 \\
\hline
\end{tabular}

Table 3. Strains in steel section at beginning of load plateau

\begin{tabular}{cccc}
\hline Specimen & $\begin{array}{c}\text { Top } \\
\text { flange } \\
(\boldsymbol{\mu \varepsilon})\end{array}$ & $\begin{array}{c}\text { Bottom } \\
\text { plate } \\
(\boldsymbol{\mu \varepsilon})\end{array}$ & $\begin{array}{c}\text { Neutral axis } \\
\text { depth }(\mathbf{m m})\end{array}$ \\
\hline BT1a & -2077 & 1564 & 123 \\
SBT2 & -1782 & 1355 & 122 \\
BT6 & 1022 & 1228 & 98 \\
SBT3 & -1309 & 948 & 125 \\
BT7 & 141 & 2292 & - \\
SBT6 & -916 & 1441 & 84 \\
BT8 & -4048 & 1764 & 150 \\
SBT5 & -153 & 1510 & 20 \\
\hline
\end{tabular}

\subsection{Shear connectors}

The shear connectors comprised the transverse steel bars and the concrete dowel that surrounded each bar where it passed through the HEB web hole. As the concrete slab began to move relative to the steel beam, the steel bars and the concrete dowel resisted this shearing action and transferred the longitudinal stresses to the steel beam, maintaining composite action between the two components. In specimens 
BT1a, BT3, BT4 and BT8, most of the shear connector bars had very low strains during the initial phase of the test, which increased rapidly during the second phase showing that they had been 'activated' in transferring stresses between the concrete and steel, as the movement between the components caused the bars to deform. In specimen BT3, the strains were predominantly compressive, whereas for BT8 these were tensile. Both tensile and compressive strains were measured in the bars in BT1a and BT4. Fig. 12 presents the strains measured in the shear connectors for BT3, where positive values indicate tension and negative values indicate compression. The largest strains occurred in the bars, closest to the ends of the beam (BA1 and BA8).

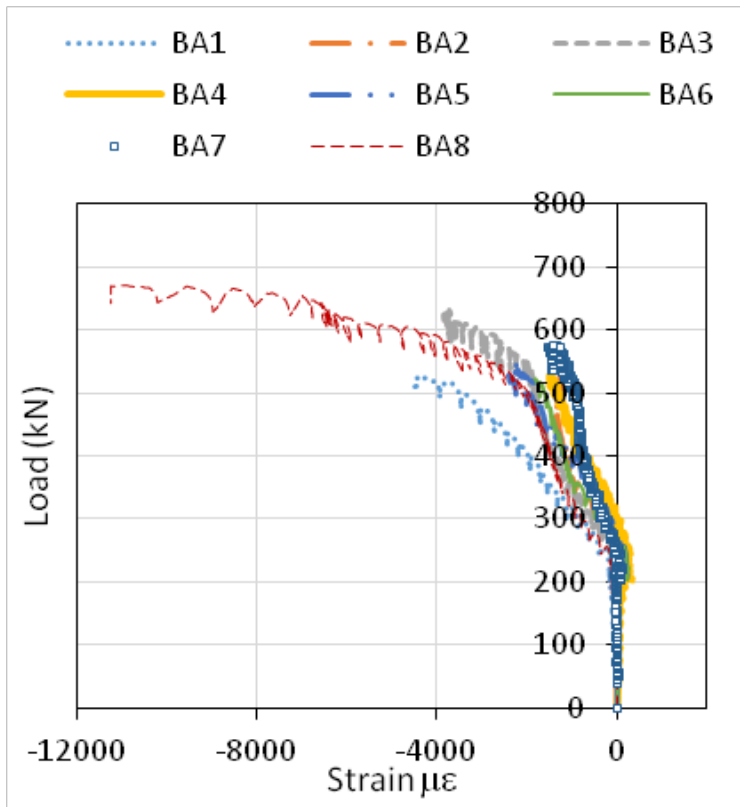

Fig. 12. Strains in shear connectors for BT3

In specimen BT7, the shear studs initially exhibited very low strains, which rapidly increased in compression during the second phase of the test, reaching between $-1000 \mu \varepsilon$ and $-2000 \mu \varepsilon$. As the load increased further, this trend was reversed and the strains became increasingly tensile during the later stages of the test. During the initial phase of the test, all shear studs exhibited similar strains but in the later stages, the two studs closest each end (SS1, SS2, SS7 and SS8) underwent the largest tensile strains. This is shown in Fig. 13.

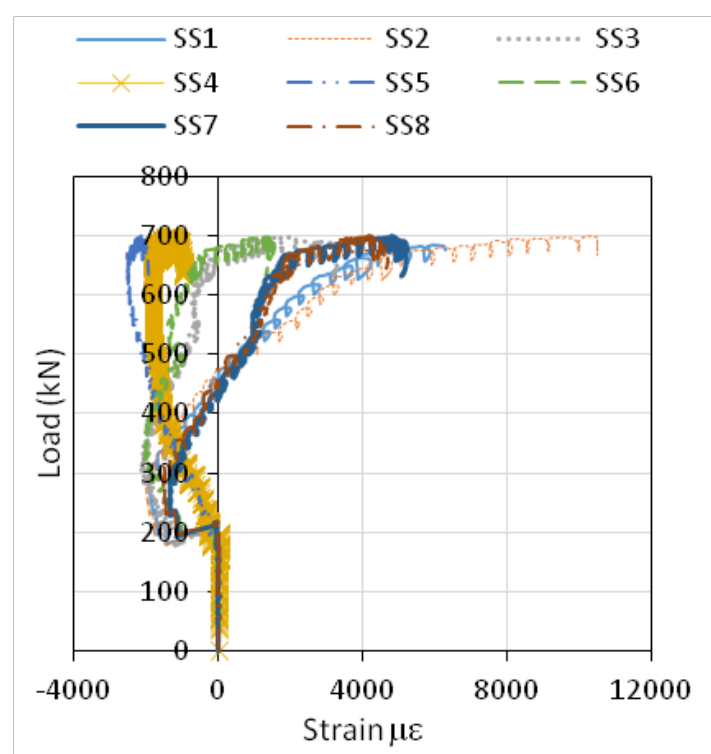

Fig. 13. Strains measured in shear studs

\section{Conclusion}

This paper presented the initial results of a series of bending tests for slim floor beams. From the initial results, it can be seen that the beams behaved in a ductile manner, achieving a total deflection exceeding span/40 and end-slips greater than $6 \mathrm{~mm}$ prior to failure. Transverse bar passing through holes in the steel beam web proved to be effective shear connectors and the size of the web hole affected the overall resistance. Further experiments will be conducted in the future to consider the effect of a uniformly distributed load and the effect of using a concrete slab without any top cover to the beam. Further analysis of the test results will lead to the development of design recommendations for this type of section.

\section{Acknowledgement}

The authors gratefully acknowledge the funding received from the European Community Research Fund for Coal and Steel under grant agreement number RFSR-CT-2015-00020. 


\section{References}

[1] Bernuzzi C, Zandonini, R. Joint action in nonsway frames with steel-concrete composite slim floor systems. Journal of Singapore Structural Steel Society 1995;6(1):75-85.

[2] Kuhlmann U, Hauf G. Querkrafttragfähigkeit von Slim-Floor Trägem, AiF research project no. 15639. Institute of Structural Design, University of Stuttgart, Stuttgart, 2011.

[3] Bernuzzi C, Gadotti F, Zandonini R. Semicontinuity in slim floor steel-concrete composite systems. Proceedings of Eurosteel 95 ed. Kounadis, A. N.. Athens, Greece; 1995:287-294.

[4] Huo BY, D'Mello CA. Shear transferring mechanisms in a composite shallow cellular floor beam with web openings. Structures 2017; 9:134-146.

[5] Chen C, Limazie T. Composite slim floor beams with innovative connections. Proceedings of the ICE - Structures and Buildings 2018;1: 29-37.

[6] Mäkeläinen P, Ma Z. Fire resistance of composite slim floor beams. Journal of Constructional Steel Research 2000:54(3):345363.

[7] CEN. European Committee for Standardization. EN 1994-1-1, Eurocode 4. Design of composite steel and concrete structures - Part 1-1: General rules and rules for buildings. Brussels; 2004. 